\title{
The E3 ubiquitin ligase RNF121 is a positive regulator of NF-kB activation
}

\author{
Naima Zemirli ${ }^{1,2,3}$, Marie Pourcelot ${ }^{1,2,3}$, Neslihan Dogan ${ }^{1,2,3}$, Aimé Vazquez ${ }^{1,2,3}$ and Damien Arnoult ${ }^{1,2,3^{*}}$
}

\begin{abstract}
Background: The nuclear factor KB (NF-KB) family members regulate several biological processes as cell proliferation and differentiation, inflammation, immunity and tumor progression. Ubiquitination plays a key role in NF-KB activation and the ubiquitylated transmitters of the NF-KB signaling cascade accumulate in close proximity to endomembranes.

Findings: We performed an unbiased siRNA library screen targeting the 46 E3 ubiquitin ligases bearing transmembrane domains to uncover new modulators of NF-KB activation, using tumor necrosis factor-a (TNF-a) receptor (TNFR) stimulation as a model. We report here the identification of a new Golgi Apparatus-resident protein, RNF121, as an enhancer of NF-KB promoter activity through the catalytic function of its RING domain. From a molecular standpoint, while knocking down RNF121 did not alter RIP1 ubiquitination and IKK activation, the proteasomal degradation of IKBa was impaired suggesting that this E3 ubiquitin ligase regulates this process. However, RNF121 did not directly ubiquitinate IKBa While they were found in the same complex. Finally, we discovered that RNF121 acts as a broad regulator of NF-KB signaling since its silencing also dampens NF-KB activation following stimulation of Toll-Like Receptors (TLRs), Nod-Like Receptors (NLRs), RIG-I-Like Receptors (RLRs) or after DNA damages.
\end{abstract}

Conclusions: These results unveil an unexpected role of Golgi Apparatus and reveal RNF121 as a new player involved in the signaling leading to NF-KB activation.

Keywords: NF-kB, Ubiquitination, E3 ubiquitin ligase, Golgi apparatus, Innate immunity

\section{Findings}

The transcription factor NF- $\mathrm{kB}$ plays pivotal roles in the regulation of a plethora biological processes, including cell proliferation and differentiation, innate and adaptive immunity, inflammation and tumor progression [1,2]. NF- $\mathrm{KB}$ is a homo or heterodimer constituted with subunits belonging to the Rel family and the NF- $\mathrm{kB}$ dimers are sequestered in the cytosol by a member of the Inhibitor of $\kappa B$ (Ikb) family [2,3].

$\mathrm{NF}-\mathrm{kB}$ is activated by many inducers. Each inducer is recognized by a receptor at the cell surface or within the cell, and its binding triggers a specific signaling pathway leading to NF- $\mathrm{KB}$ activation [2,3]. Each pathway involves the organization of signaling protein complexes, the formation of polyubiquitin chains acting as binding agents on specific transmitters and the action of kinases $[4,5]$. Nevertheless, all these complexes have a point in common:

\footnotetext{
* Correspondence: damien.arnoult@inserm.fr

'INSERM, UMR_S 1014, Hôpital Paul Brousse, Villejuif 94800, France

2Université Paris-Sud P11, Orsay 91400, France

Full list of author information is available at the end of the article
}

they recruit and activate, through specific ubiquitylated transmitters, the inhibitor of NF-kB (IкB) kinase (IKK) complex, which consists of two catalytic kinases, IKK $\alpha$ and IKK $\beta$, and the regulatory subunit NEMO (also known as IKK $\gamma$ ) [6]. IKK then phosphorylates the inhibitory IKB proteins, promoting their Lys ${ }^{48}\left(\mathrm{~K}^{48}\right)$-linked ubiquitination and proteasomal degradation [7]. NF- $\mathrm{kB}$ dimers subsequently enter the nucleus, where they initiate the transcription of their target genes, including genes encoding pro-inflammatory cytokines or anti-apoptotic proteins [1].

As we recently reported an accumulation of the ubiquitylated transmitters leading to NF- $\mathrm{BB}$ activation to the endomembrane fraction [8], we set up a siRNA screen with two oligoribonucleotides against each of the 46 membrane spanning E3 ubiquitin ligases [9] (Additional file 1) to uncover new regulators of NF- $\mathrm{kB}$ activation, using tumor necrosis factor- $\alpha$ (TNF- $\alpha$ ) receptor (TNFR) stimulation as a model. Indeed, engagement of TNFR promotes a rapid NF- $\mathrm{KB}$ activation through the recruitment to the receptor of the adaptor protein TRADD together with the E3 ubiquitin ligases c-IAPs and TRAF2, which 
are responsible for catalyzing the polyubiquitination of the kinase RIP1 that acts as a specific ubiquitylated transmitter for this pathway [10]. The impact of the knock down of the 46 membrane spanning E3 ubiquitin ligases was assessed in a gene reported assay and silencing of the key regulator of TNFR-mediated NF- $\mathrm{kB}$ TRAF2 was used as a control (Figure 1A, B; see Additional file 2 for detailed Methods description). Among the top hits was RNF121 (Figure 1A). RNF121 is part of a chromosomal band (11q13) that may contain a high penetrance gene for breast cancer [11]. We then used two additional siRNA sequences against RNF121 and confirmed that TNFR-mediated NF- $k B$ activation was decreased, further validating the results from our initial screen (Figure 1C). Interestingly, the enforced expression of RNF121 activated NF- $k B$ and NF- $k B$ activation following TNFR stimulation was potentiated in a dose dependent-manner (Figure 1D). RNF121 specifically triggered NF- $\mathrm{kB}$ activation because it did not stimulate the expression of IFN $\beta-$-, ISRE-, NFAT-,
AP1- or p53-dependent reporter genes (data not shown). The ability of RNF121 to activate NF-kB was dependent on the catalytic activity of its RING domain, because the RNF121 ${ }^{\text {C226-229A }}$ mutant gave significantly lower levels of NF- $\mathrm{kB}$ activation (Figure 1E). Based on the available RING finger protein structure $[12,13]$, the replacement of the cys-226 and 229 residues with an alanine was predicted to prevent $\mathrm{Zn}^{2+}$ coordination, thereby impeding the overall function of the RING domain as assessed by the level of auto-ubiquitination (Figure 1F).

RNF121 is a 327 amino acids protein with a RING domain, and six transmembrane domains that have reported to anchor the protein at the endoplasmic reticulum (ER) in the nematode [14] (Figure 2A). Accordingly, both ectopically expressed and endogenous RNF121 were detected in fractions enriched with intracellular organelles (Figure 2B and C). Next, analysis of the cellular localization of RNF121 by immunofluorescence showed that Myc-tagged or endogenous RNF121 specifically co-localized

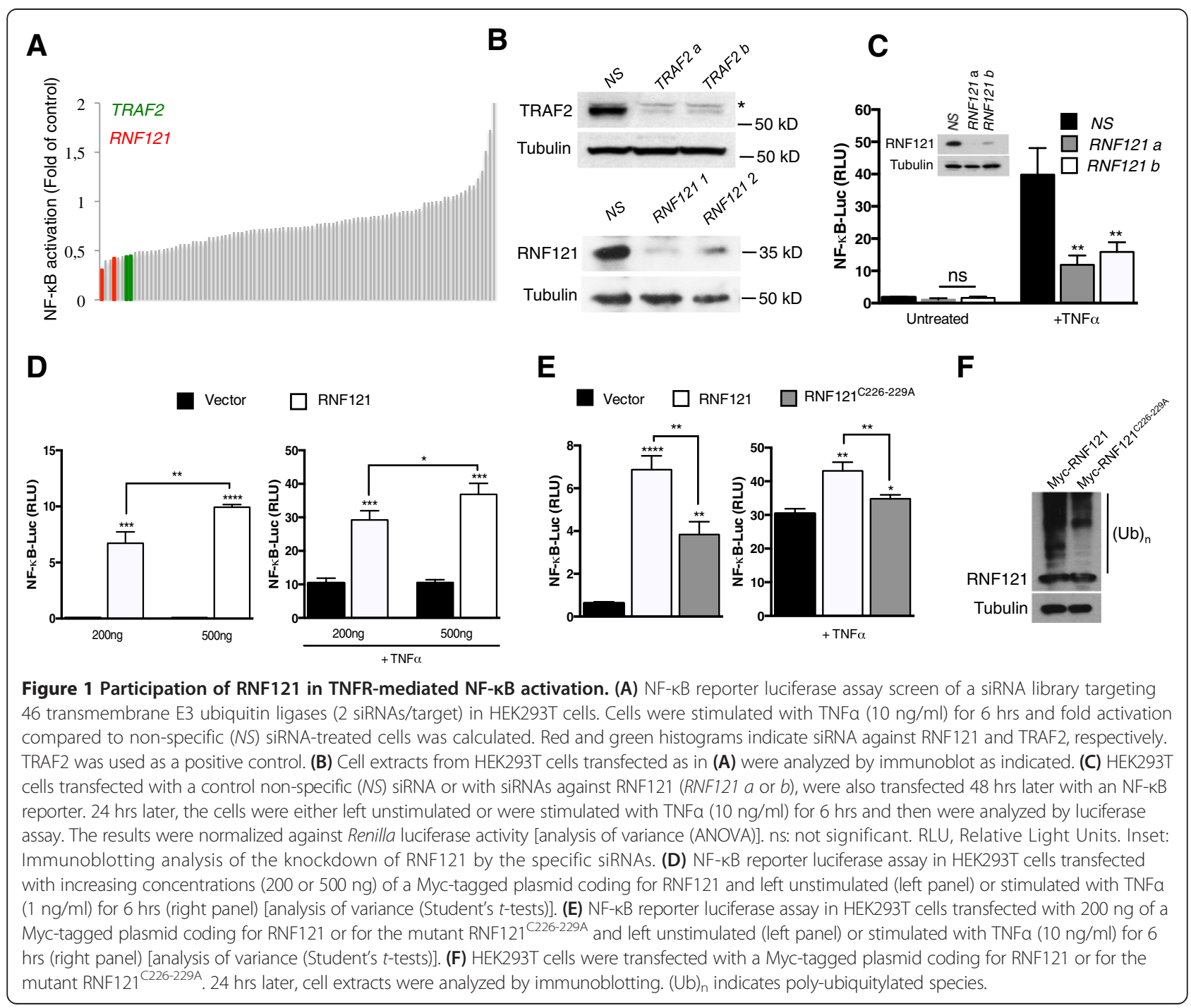




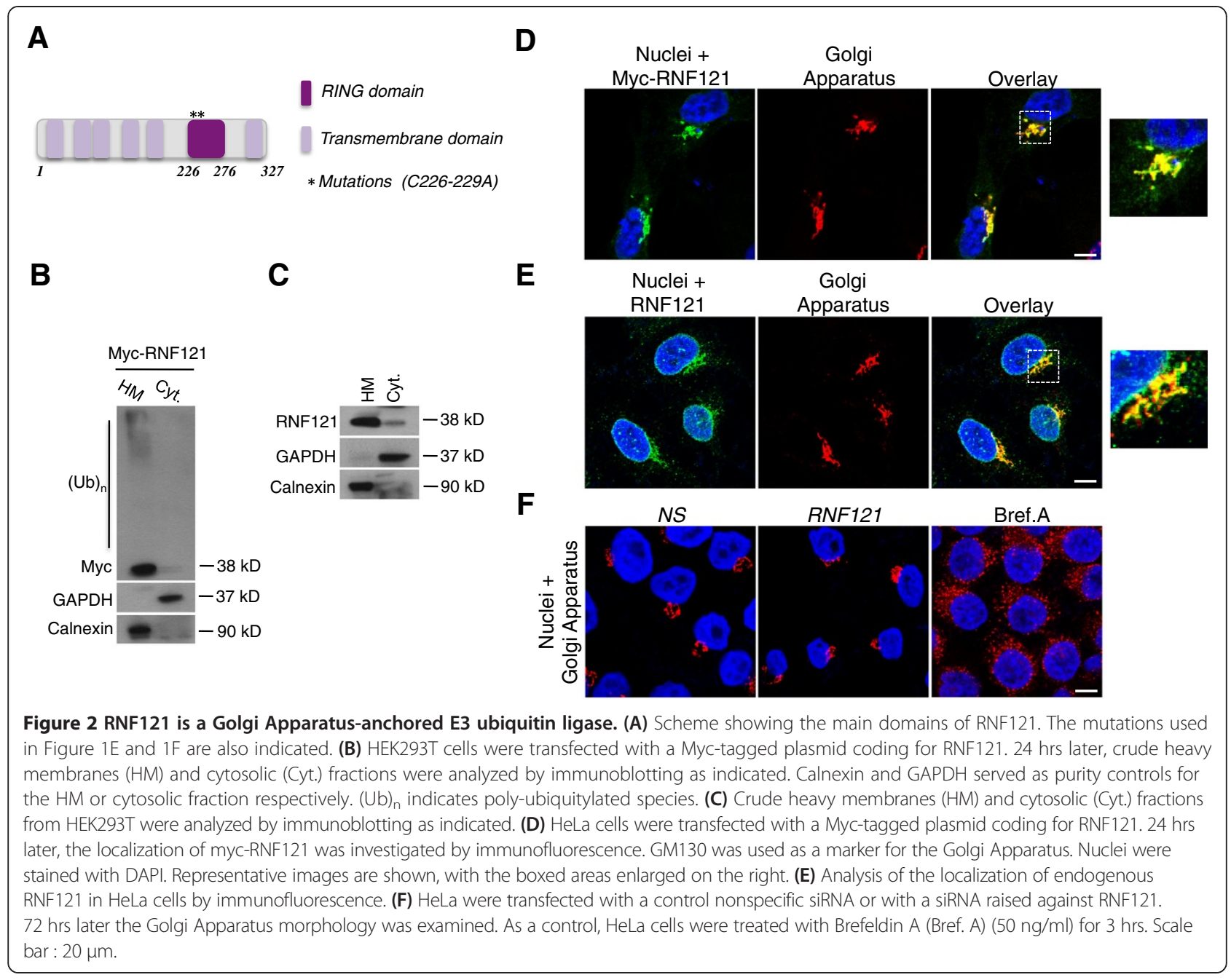

with the Golgi Apparatus (Figure 2D and E). Finally, while RNF121 appeared to be anchored in the Golgi Apparatus, silencing of this protein did not seem to affect the morphology of this organelle unlike a Brefeldin A treatment (Figure 2F), and the cell viability was not significantly modified (data not shown).

While RNF121 and RNF175 are close homologs (Additional file 3A), silencing of RNF175 had no overt effect on TNFR-mediated NF- $\mathrm{kB}$ activation (Additional file 3B) suggesting a specificity of RNF121 in this pathway. Next, as for RIP1, RNF121 silencing impaired the secretion of the cytokine IL- 8 , a target gene of NF- $\mathrm{kB}$ [1], further confirming the participation of RNF121 in TNFR-mediated NF- $\kappa$ B activation (Figure 3A). RNF121 silencing also sensitized cells to TNF $\alpha$-mediated cell death (Additional file 4) confirming again the involvement of RNF121 in NF- $\mathrm{kB}$ activation as NF- $\mathrm{kB}$ protects from $\mathrm{TNF} \alpha$-mediated cell death through the expression of anti-apoptotic proteins [1]. Because ubiquitination of RIP1 is the central event in TNFR signaling $[4,5,10]$, we next investigated whether RNF121 silencing impacts this process. Immunoprecipitation of the TNFR indicated that RIP1 ubiquitination is not altered when RNF121 was knocked down (Figure 3B) and the accumulation of ubiquitylated RIP1 in the heavy membrane fraction was not impeded [8] (Figure 3C). Unexpectedly, RIP1 deubiquitination in RNF121-silenced cells seemed to be delayed (Figure 3C). Nevertheless and as expected, cell fractionation experiments showed reduced p65/p50 NF- $\kappa B$ dimer levels in nuclear fractions from RNF121-silenced cells (Figure 3D) and the decreased relocation of p65 into the nuclei was confirmed by confocal microscopy (Figure $3 \mathrm{E}$ and F). These observations were in agreement with the finding that the proteasomal degradation of I $\mathrm{KB} \alpha$ was hampered (Figure 3C, G, H and Additional file 5). Nevertheless, as for the MAPKs extracellular signal-regulated kinase (ERK), ІкB $\alpha$ phosphorylation was not inhibited when RNF121 was knocked down (Figure 3G) in accord with the observation that activation of the IKK complex was not reduced either (Figure 3H). Together, these results suggested that RNF121 is likely implicated in the control of the proteasomal degradation of 


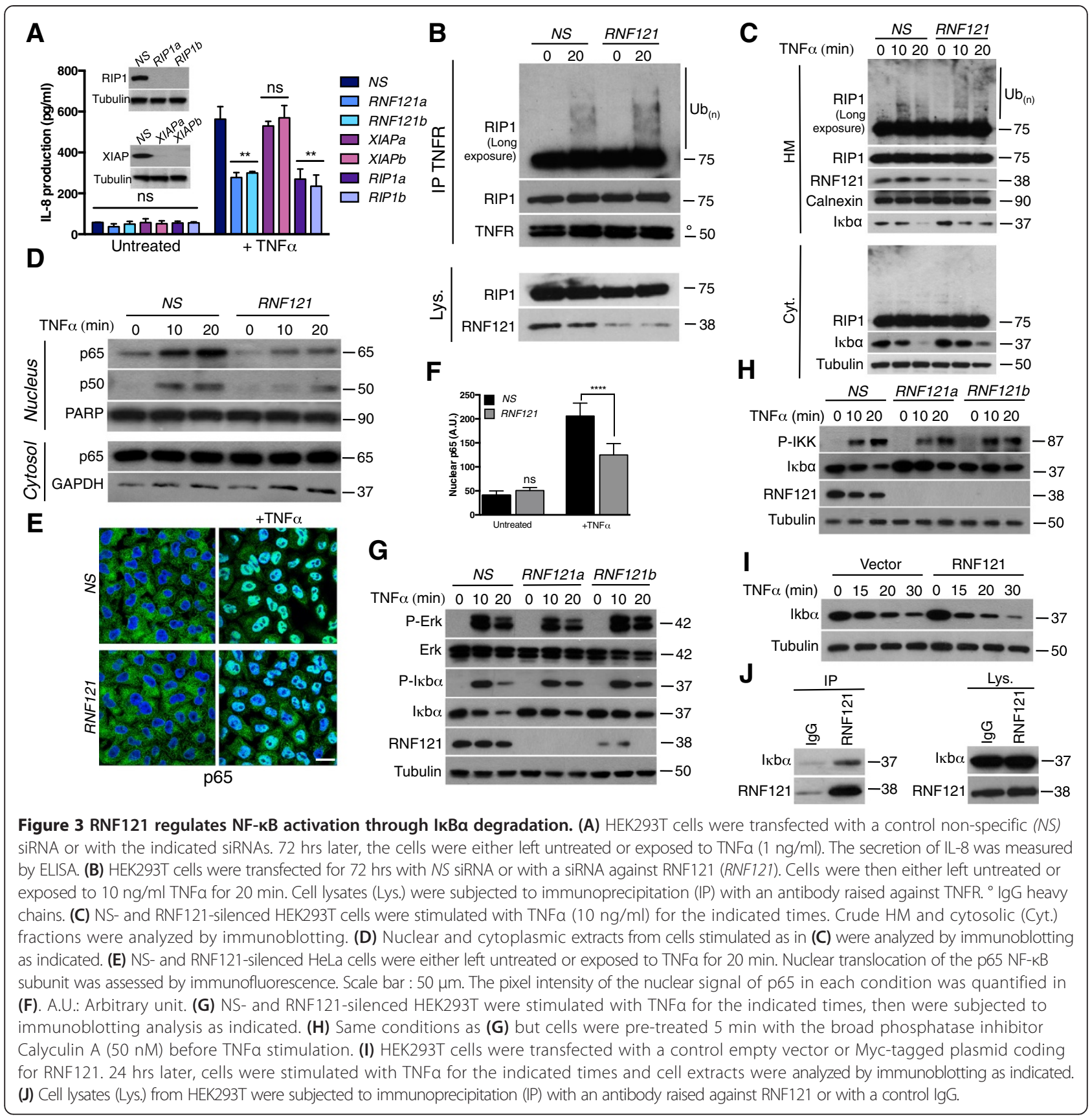

IкB $\alpha$. Accordingly, ectopic expression of RNF121 accelerated I $\mathrm{KB} \alpha$ degradation following TNF $\alpha$ exposure (Figure 3I). Immunoprecipitation of endogenous RNF121 demonstrated that both proteins are in the same complex (Figure 3J) and a pool of IкB $\alpha$ co-localized with RNF121 (Additional file 6). However, RNF121 did not seem to induce the ubiquitination of IKB $\alpha$ (Additional file 7A and B) likely because both proteins did not directly interact (Additional file 7A and $\mathrm{C}$ ).

As RNF121 seemed to regulate IKB $\alpha$ degradation, a general feature in the process of NF- $\mathrm{kB}$ activation [3,7], we then investigated whether RNF121 silencing affects
NF- $\kappa B$ activation upon stimulation of innate immunity receptors [15]. We observed that RNF121 silencing also inhibited I $\mathrm{\kappa} B \alpha$ degradation and ensuing NF- $\mathrm{KB}$ activation following Toll-Like-Receptor 3 (TLR3) stimulation with poly (I:C) (Figure 4A) while it had no effect on the stimulation of the IFN $\beta$ promoter (Figure 4B) confirming the specificity of RNF121 in the NF- $\mathrm{kB}$ pathway. Similarly, RNF121 knock down impaired NF- $\mathrm{BB}$ activation after stimulation of Toll-Like-Receptor 4 (TLR4), retinoic acid-inducible gene 1 (RIG-I), nucleotide-binding oligomerization domain-containing protein 1 (NOD1) 


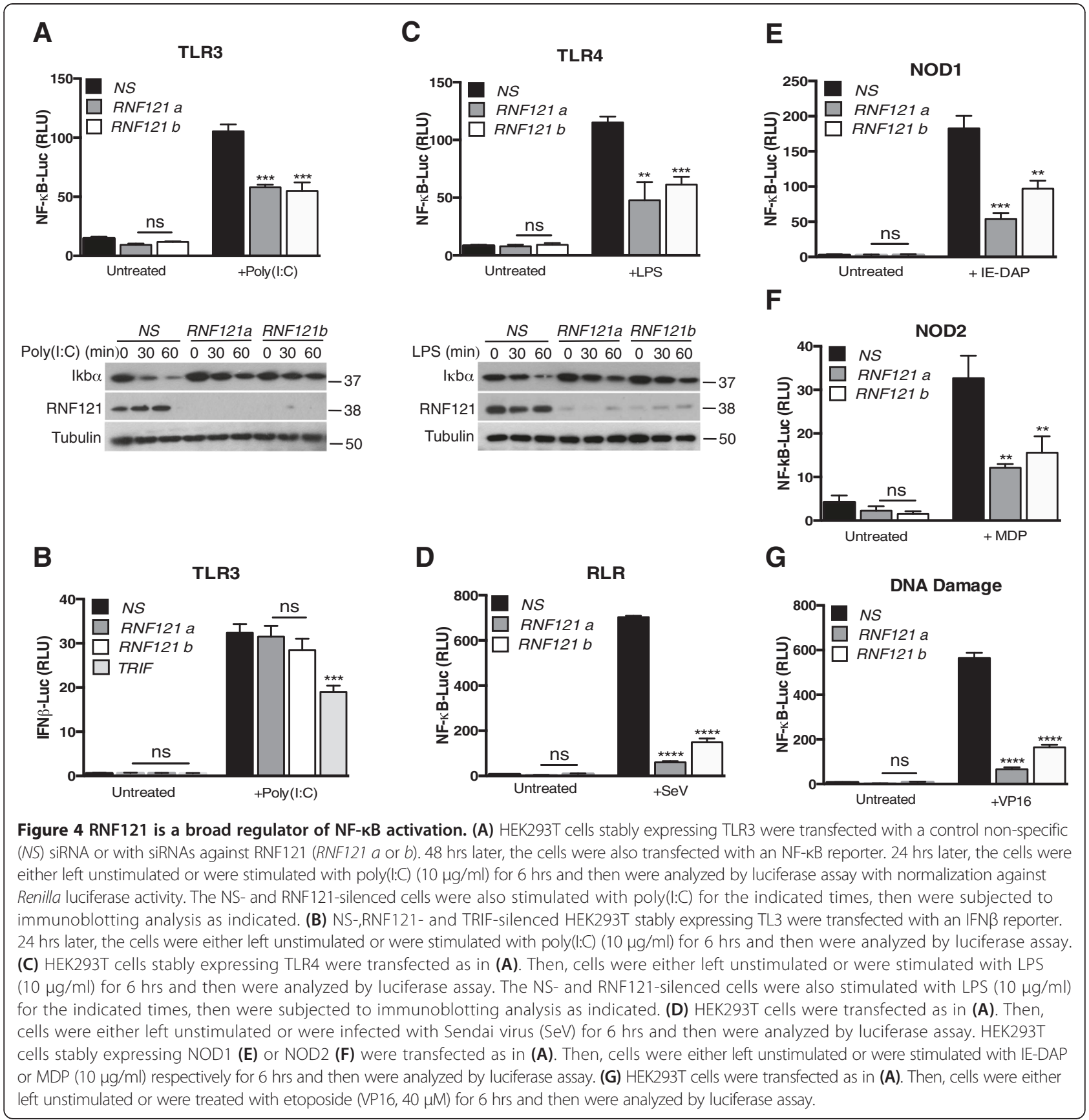

and NOD2 with lipopolysaccharide (LPS), viral RNAs, $\gamma$-D-Glu-mDAP from peptidoglycan (IE-DAP) or muramyl dipeptide (MDP) respectively (Figure $4 \mathrm{C}, \mathrm{D}, \mathrm{E}$ and F). Finally, in cells exposed to the DNA-damaging agent etoposide, which relies on NEMO SUMOylation and phosphorylation to convey NF- $\mathrm{kB}$ activity [16], the transcription factor activation was reduced again (Figure 4G), suggesting that RNF121 acts as a broad regulator of $\mathrm{NF}-\mathrm{kB}$ signaling.

In summary, we provide evidence that RNF121, a Golgi apparatus-anchored E3 ubiquitin ligase, participates in
NF- $\mathrm{kB}$ activation. When overexpressed, RNF121 promotes NF- $\mathrm{B}$ activity. While ubiquitination of specific key transmitters is required for the $N F-\kappa B$ signaling [2-5], our data indicate that ubiquitination of RIP1 (Figure 3B and C), IRAK1 or RIP2 (data not shown) following the stimulation of TNFR, TLR4 or NOD1 respectively, was not affected when RNF121 was silenced. Moreover, although the phosphorylation of both IKK and its target IkB $\alpha$ was normal in RNF121 siRNAtransfected cells, I $\mathrm{K} B \alpha$ degradation and the resulting p65/p50 NF-kB dimers redistribution were impaired. 
These observations suggest that RNF121 is involved in the proteasomal degradation of ІкB $\alpha$ [7].

Further works are required to delineate the molecular framework employed by RNF121 to regulate IкBa degradation. IкB $\alpha$ degradation involves a $\mathrm{K}^{48}$-linked ubiquitination [7] that is mediated by a specific E3 ubiquitin ligase $\mathrm{SCF}^{\beta-\operatorname{TrCP}}$ [17-19]. The F-box component of this $\mathrm{E} 3, \beta-\mathrm{TrCP}$, recognizes the IkB $\alpha$ degron formed following phosphorylation by IKK and thus couples IкB $\alpha$ phosphorylation to ubiquitination [7]. While endogenous RNF121 and $I \kappa B \alpha$ were found in the same immuno-complex (Figure 3J), RNF121 did not appear to directly ubiquitinate $\mathrm{I} \kappa \mathrm{B} \alpha$ (Additional file $7 \mathrm{~A}$ ). We then hypothesize that RNF121 controls SCF ${ }^{\beta-T r C P}$ function on IkB $\alpha$ in a complex through ubiquitination and this aspect merits future exploration. Indeed, the Nedd8 ubiquitin-like molecule regulates the assembly and catalytic activity of the SCF complex [20]. Interestingly, a significant pool of $\beta$-TrCP co-localized with the Golgi Apparatus where is anchored RNF121 (Additional file 8) and in preliminary experiments, endogenous RNF121 and $\beta-\operatorname{TrCP}$ were detected in the same complex (data not shown). However, we do not rule out the hypothesis that RNF121 also modulates the ubiquitination of other proteins of the SCF complex as Skp1, Cul1 or Rbx1/Roc1 [7].

In conclusion, over and above its previously known roles, Golgi Apparatus seems to be also involved in NF- $\mathrm{kB}$ activation via the E3 ubiquitin ligase RNF121.

\section{Additional files}

\section{Additional file 1: Design of the siRNA library. \\ Additional file 2: Methods description.}

Additional file 3: RNF175, a close homolog of RNF121, does not regulate NF-KB activation.

Additional file 4: RNF121 silencing sensitizes cells to TNFa-mediated apoptosis.

Additional file 5: RNF121 silencing delays ІкBa degradation.

Additional file 6: A pool of IKBa co-localizes with RNF121.

Additional file 7: RNF121 does not directly ubiquitinate IKBa. $(\Pi \Delta \Phi 597 \mathrm{k} \beta)$

Additional file 8: Intracellular localization of $\beta$-TrCP.

\section{Abbreviations}

AP-1: Activator protein 1; ERK: Extracellular signal-regulated Kinases; IFN: Interferon; IKBs: Inhibitors of NF-KB; IKK: IKBs kinase; ISRE: IFN stimulated response element; MAPK: Mitogen-activated protein Kinase; NFAT: Nuclear factor of activated T-cells; NEMO: NF-KB essential modulator; NF-KB: Nuclear factor-KB; NLR: NOD-Like Receptor;

NOD: Nucleotide-binding oligomerization domain-containing protein; RIG-I: Retinoic acid-inducible gene I; RIP1: Receptor interacting protein 1; RLR: RIG-I-like receptor; RNF121: Ring finger protein 121; TLR: Toll-like receptor; TNFa: Tumor necrosis factor a; TRADD: TNF Receptor type 1-associated death domain protein; TRAF: TNF receptor-associated factor.

\section{Competing interests}

The authors declare that they have no competing interests.
Authors' contributions

NZ designed and conducted most experiments, analyzed the data and wrote the manuscript. MP, ND conducted experiments and analyzed the data. AV analyzed the data. DA conceived the project, conducted experiments, analyzed the data and wrote the manuscript. All authors have read and approved the final version of the manuscript.

\section{Acknowledgements}

We thank N. Bidère, E. Hatchi, K. Poalas and G. Ambroise for helpful discussions. This work was supported by grants from Fondation ARC, Ligue Nationale contre le Cancer (Equipe Labellisée) and ANRS. NZ and MP are supported by fellowships from Université Paris Sud.

\section{Author details}

'INSERM, UMR_S 1014, Hôpital Paul Brousse, Villejuif 94800, France. ${ }^{2}$ Université Paris-Sud P11, Orsay 91400, France. ${ }^{3}$ Equipe Labellisée Ligue contre le Cancer, Villejuif 94800, France.

Received: 13 May 2014 Accepted: 21 October 2014

Published online: 12 November 2014

\section{References}

1. Ben-Neriah Y, Karin M: Inflammation meets cancer, with NF-kappaB as the matchmaker. Nat Immunol 2011, 12:715-723.

2. Hayden MS, Ghosh S: NF-kappaB, the first quarter-century: remarkable progress and outstanding questions. Genes Dev 2012, 26:203-234.

3. Napetschnig J, Wu H: Molecular basis of NF-kappaB signaling. Annu Rev Biophys 2013, 42:443-468.

4. Bhoj VG, Chen ZJ: Ubiquitylation in innate and adaptive immunity. Nature 2009, 458:430-437.

5. Skaug B, Jiang $X$, Chen ZJ: The role of ubiquitin in NF-kappaB regulatory pathways. Annu Rev Biochem 2009, 78:769-796.

6. Israel A: The IKK complex, a central regulator of NF-kappaB activation Cold Spring Harb Perspect Biol 2010, 2:a000158.

7. Kanarek N, Ben-Neriah Y: Regulation of NF-kappaB by ubiquitination and degradation of the IkappaBs. Immunol Rev 2012, 246:77-94.

8. Alexia C, Poalas K, Carvalho G, Zemirli N, Dwyer J, Dubois SM, Hatchi EM, Cordeiro N, Smith SS, Castanier C, Le Guelte A, Wan L, Kang Y, Vazquez A, Gavard J, Arnoult D, Bidere N: The Endoplasmic Reticulum Acts as a Platform for Ubiquitylated Components of Nuclear Factor kappaB Signaling. Sci Signal 2013, 6:ra79.

9. Li W, Bengtson MH, Ulbrich A, Matsuda A, Reddy VA, Orth A, Chanda SK Batalov S, Joazeiro CA: Genome-wide and functional annotation of human E3 ubiquitin ligases identifies MULAN, a mitochondrial E3 that regulates the organelle's dynamics and signaling. PLOS One 2008, 3:14887.

10. Walczak H: TNF and ubiquitin at the crossroads of gene activation, cell death, inflammation, and cancer. Immunol Rev 2011, 244:9-28.

11. Rosa-Rosa JM, Pita G, Gonzalez-Neira A, Milne RL, Fernandez V, Ruivenkamp C, van Asperen CJ, Devilee P, Benitez J: A 7 Mb region within 11 q13 may contain a high penetrance gene for breast cancer. Breast Cancer Res Treat 2009, 118:151-159.

12. Bottomley MJ, Stier G, Pennacchini D, Legube G, Simon B, Akhtar A, Sattler M, Musco G: NMR structure of the first PHD finger of autoimmune regulator protein (AIRE1). Insights into autoimmune polyendocrinopathy-candidiasisectodermal dystrophy (APECED) disease. J Biol Chem 2005, 280:1 1505-11512.

13. Katoh S, Hong C, Tsunoda Y, Murata K, Takai R, Minami E, Yamazaki T, Katoh E: High precision NMR structure and function of the RING-H2 finger domain of EL5, a rice protein whose expression is increased upon exposure to pathogen-derived oligosaccharides. J Biol Chem 2003, 278:15341-15348.

14. Darom A, Bening-Abu-Shach U, Broday L: RNF-121 is an endoplasmic reticulum-membrane E3 ubiquitin ligase involved in the regulation of beta-integrin. Mol Biol Cell 2010, 21:1788-1798.

15. Akira S, Uematsu S, Takeuchi O: Pathogen recognition and innate immunity. Cell 2006, 124:783-801.

16. McCool KW, Miyamoto S: DNA damage-dependent NF-kappaB activation: NEMO turns nuclear signaling inside out. Immunol Rev 2012, 246:311-326.

17. Spencer E, Jiang J, Chen ZJ: Signal-induced ubiquitination of IkappaBalpha by the F-box protein Slimb/beta-TrCP. Genes Dev 1999, 13:284-294.

18. Winston JT, Strack P, Beer-Romero P, Chu CY, Elledge SJ, Harper JW: The SCFbeta-TRCP-ubiquitin ligase complex associates specifically with 
phosphorylated destruction motifs in IkappaBalpha and beta-catenin and stimulates IkappaBalpha ubiquitination in vitro. Genes Dev 1999, 13:270-283.

19. Yaron A, Hatzubai A, Davis M, Lavon I, Amit S, Manning AM, Andersen JS, Mann M, Mercurio F, Ben-Neriah Y: Identification of the receptor component of the IkappaBalpha-ubiquitin ligase. Nature 1998, 396:590-594.

20. Read MA, Brownell JE, Gladysheva TB, Hottelet M, Parent LA, Coggins MB, Pierce JW, Podust VN, Luo RS, Chau V, Palombella VJ: Nedd8 modification of cul-1 activates SCF(beta(TrCP))-dependent ubiquitination of IkappaBalpha. Mol Cell Biol 2000, 20:2326-2333.

doi:10.1186/s12964-014-0072-8

Cite this article as: Zemirli et al.: The E3 ubiquitin ligase RNF121 is a positive regulator of NF-KB activation. Cell Communication and Signaling 2014 12:72.

\section{Submit your next manuscript to BioMed Central and take full advantage of:}

- Convenient online submission

- Thorough peer review

- No space constraints or color figure charges

- Immediate publication on acceptance

- Inclusion in PubMed, CAS, Scopus and Google Scholar

- Research which is freely available for redistribution 